\title{
A Biometric Identification Course for eSience Virtual Lab
}

\author{
Samir Akrouf, Selmani Larbi, Boubetra Djamel, and Mostefai Messaoud
}

\begin{abstract}
Determining the identity of a person automatically is still an actual problem. There is an urgent need to have automatic and reliable authentication systems in order to combat fraud and meet the requirements for different areas ranging from international border stations to accessing personal information. Biometrics is an alternative to the old methods of identification. It involves identifying persons from their physical or behavioral characteristics. Face, fingerprint, iris, etc, are examples of physical characteristics. This course aims to introduce first basic concepts related to the recognition of individuals, based on their physiological or behavioral biometric characteristics, to students and allow them to study the key techniques to achieve reliable systems for biometric recognition. In This paper we will present the architecture of the course which will be held on a virtual laboratory. The course objective is to give the student different skills which are necessary in this field of study. The course is divided in several parts; each one will present a specific topic and will provide different notions in order to let students understand theoretical concepts by practicing.
\end{abstract}

Index Terms - Virtual lab, biometric identification, biometric traits, biometric systems.

\section{INTRODUCTION}

Nowadays we observe a great development in education; this is mainly due to the technological evolution and the large use of internet and personal computers. This new linked world offers lots of possibilities and makes it easy for students to enroll to a specific course and study remotely [1].

We at the University of Bordj Bou Arreridj are involved in a TEMPUS project; its acronym is eSience which stands for rESeau maghrébIn de laboratoirEs à distaNCE, it aims to link three virtual laboratories around the Maghreb countries namely Algeria, Tunisia and Morocco. The project is coordinated by the University of Bordeaux 1, France with the participation of many other European partners. These laboratories will propose practical and theoretical teaching units to students and will be part of their degree program. The project is divided in several working packages (WPS). One of these WPS is the definition and the conception of the teaching units; we are in charge of two of them.

In this paper we are defining the architecture of one of these two units which is entitled "Biometric Identification" [2]. The objective of this unit is to give to the students the following:

Manuscript received June 12, 2013; revised September 16, 2013. This work was supported in part by the European Commission.

The authors are with the University of Bordj Bou Arreridj Algeria (e-mail samir.akrouf@univ-bba.dz, 1.selmani@laposte.net, boubetra@gmail.com, mostefaimess@gmail.com).
- A general introduction to Biometric

- A definition of the principles used in Biometric Systems

- Biometric Identification

- Multimodal Biometric Identification

- Case Studies

\section{THE COURSE ARCHITECTURE}

The course is divided in 5 parts. Each one will present several notions which are essentials and let the student direct his learning since he will take the necessary time to assimilate these notions. The following is the list of these parts:

1) Introduction

2) Biometric Systems

3) Biometric Identification

4) Multimodal Biometric Identification

5) Case Studies

We will describe these different parts in the following sections beginning by the main interface leading to the usage of our elab and then introducing the general architecture of the course (see Fig. 1).

\section{A. Introduction}

In this part of the course we will study the goals and advantages behind studying Biometrics. We will define the biometric recognition and discuss the advantages and disadvantages and what are we expecting from it. We will introduce several biometric modalities and give examples of its applications [3].

\section{B. Biometric Systems}

Here we will pass through several aspects which will depict the biometric systems and their architectures [4]. The following points will be studied:

- Verification and Identification (here the user may cooperate or may not)

- Biometric System Architecture and comparison of their scores

- The process of Enrolment and Training

\section{Biometric Systems Performances}

The performances of Biometric Systems are done by evaluating their error rates [5]:

- False match rate

- False non-match rate

- Failure to acquire

- Failure to enrol

- False acceptance rate

- False rejection rate

- Equal error rate

D. Multimodal Biometric Identification 


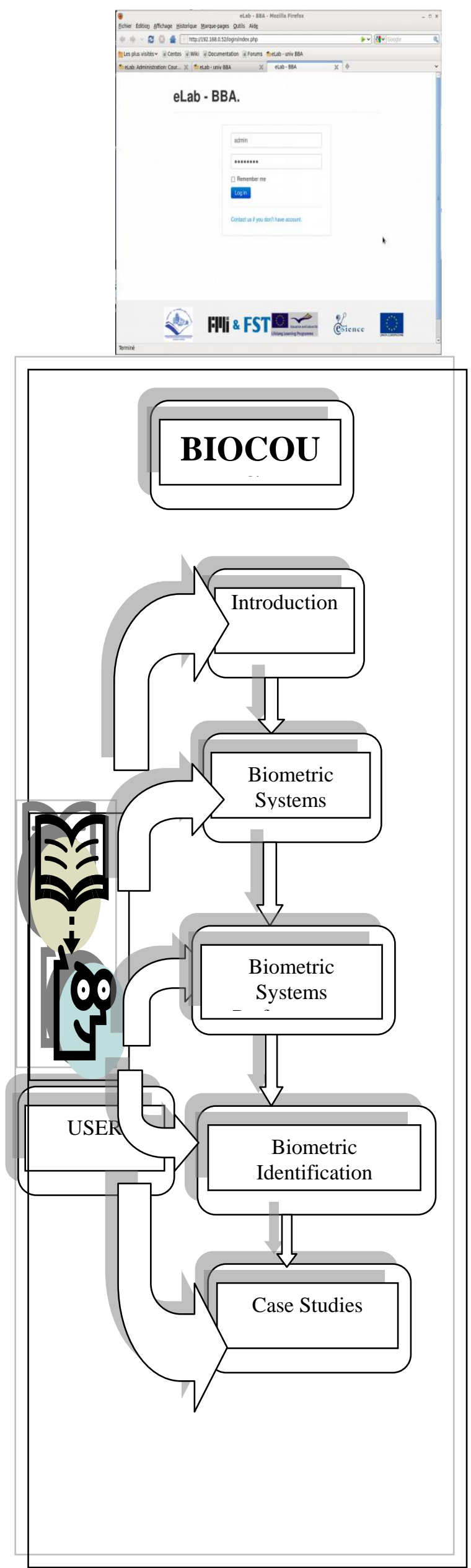

Fig. 1. Course architecture.
Here we will show that Biometric Systems with only one modality are not of high performance and this is due to many factors that will be discussed. We will talk about fusion of modalities and study the different levels of fusion [6], [7]:

- Multi-modal, Multi-algorithm, Multi-instance

- The fusion levels:

1) Score-level

2) Decision-level

3) $\quad \ldots . .$.

\section{E. Case Studies}

As stated earlier in this paper one of the objectives of this course is to give the student the possibility to view and test all the theoretical notions by viewing examples and as part of this course they have to conceive biometric systems and test them with real data acquired by acquisition systems such as scanners and cameras. The following are the systems they have to deal with [8]-[10]:

- Biometric Identification System using face

- Biometric Identification System using speech

- Biometric Identification System using face and speech

Students will have to pass through different identification processes using different modalities such as face voice and fingerprints. The following paragraph gives a simple idea of the scenarios used in the learning process.

\section{F. Biometric Identification System Using Face scenario}

In the following we will present one of the technical works and experimentations that the students will be passing through in order to understand the process of identifying a person by using his face. The following chart shows the stages needed for the identification process:

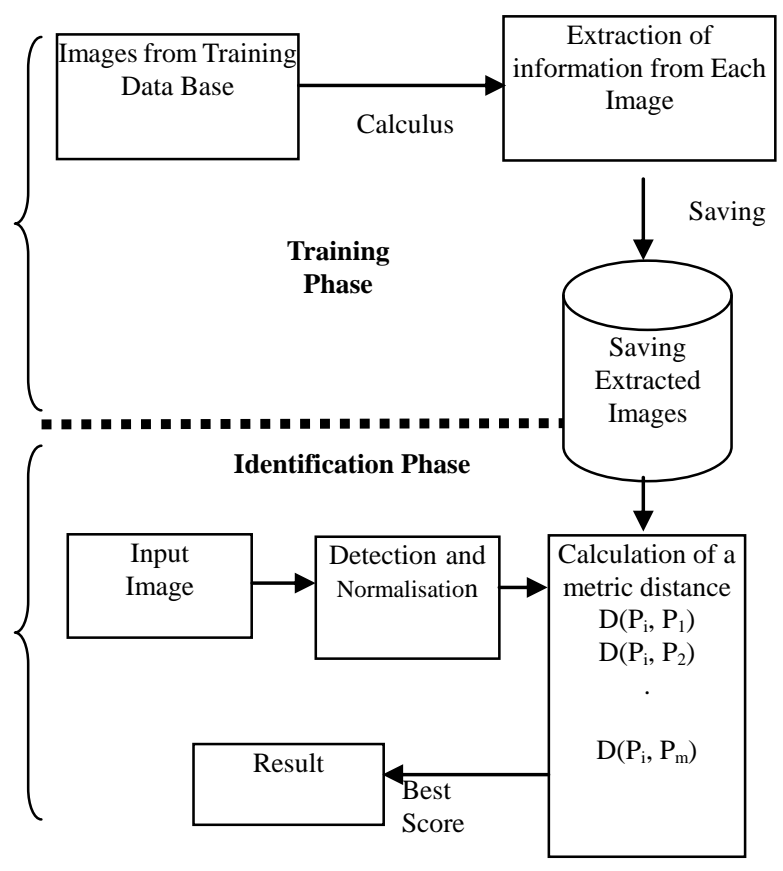

Fig. 2. Recognition algorithm stages.

The student will first be asked to introduce an image, or he can use his web camera to take a picture, then the process begins and takes the student in a virtual tour showing him the different stages, from the extraction stage until the final stage where either the person is identified or not. The experiment is 
performed by using images from a data base which was created in our University, it is called BBAFaces. The following figure shows an example of the data base:

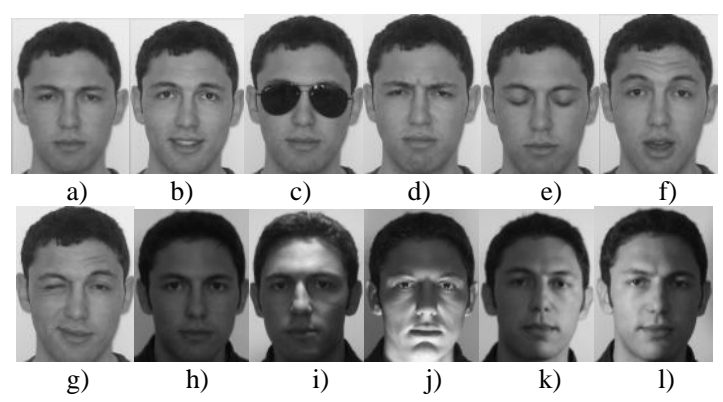

Fig. 3. Example from BBAFaces a): normal, b): happy, c): glasses, d): sad, e): sleepy, f): surprised, g): wink, h): dark, i): top light, j): bottom light, k): left light, 1): right light.

For pedagogical reasons we will use different methods for identification (such as PCA [11], DCT [12] and a Hybrid one [8]) and calculate the rate of identification for each one.

\section{PERSPECTIVES}

As we have mentioned at the beginning of this paper, this course will be part of a virtual laboratory and our students will be using it as a part of their degree program. We will evaluate its usage and see how it will affect their understanding and their results at the end of each semester. We are expecting better results since students will have the time and the opportunity to go through the different parts of the course as many times as they want to. They will proceed step by step and we will ask them to give us their experience by using a blog which will permit us to communicate with them instantly.

\section{CONCLUSION}

The principal achievement of this paper is the presentation of the general architecture of a Multimodal Biometric Identification course which will be on a virtual lab and will be used by our students. This model is under development and will be enriched by many other examples and theoretical notions. This course and others will have a great impact on the process of studying and will be certainly of great help to students since they can study at their own pace and from everywhere.

\section{REFERENCES}

[1] I. Kantzavelou, "A Virtual Lab Model for an Introductory Computer Science Course," FACTA UNIVERSITATIS (NI `S) SER.: ELEC, ENERG, vol. 18, no. 2, August 2005, pp. 263-274.

[2] A. K. Jain, "Biometric recognition," Nature, vol. 449, pp. 38-40, September 2007.

[3] A. K. Jain, A. Ross, and S. Prabhakar. "An introduction to biometric recognition," IEEE Transactions on Circuits and Systems for Video Technology, vol. 14, no. 1, pp. 4-20, January 2004.

[4] T. Mansfield, G. Kelly, D. Chandler, and J. Kane, "Biometric product testing final report," Internal report, Centre for Mathematics and Scientific Computing, National Physical Laboratory, 2001.
[5] A. K. Jain and A. Ross, "Multibiometric systems," Communications of the ACM, special issue on multimodal interfaces, vol. 47, no. 1, pp. 34-40, January 2004.

[6] A. K. Ross, "An introduction to multibiometrics," in Proc. the 15th European Signal Processing Conference (EUSIPCO), pp. 20-24, Poznan, Poland, 2007.

[7] A. Ross, A. K. Jain, and J.-Z. Qian, "Information fusion in biometrics," in Proc. 3rd International Conference on Audio- and Video-Based Person Authentication (AVBPA), pp. 354-359, Sweden, 2001.

[8] S. Akrouf, S. M. Amine, C. Abdesslam, M. Mostefai, and Y. Chahir, "Face Recognition Using PCA and DCT," 2009 Fifth International Conference on Mems Nano and Smart Systems, 28-30 December 2009, Dubai UAE.

[9] A. Samir, M. Abbas, B. Nacéra, and M. Mostefai, "An Automatic Speaker Recognition System," 2009 the 2nd International Conference on Advanced Computer Theory Engineering (ICACTE 2009), Cairo, Egypt, September 25-27, 2009.

[10] S. Akrouf, B. Yahia, M. Messaoud, and Y. chahir, "A Multi-Modal Recognition System Using Face and Speech," IJCSI International Journal of Computer Science Issues, vol. 8, issue 3, May 2011, ISSN: 1694-0814.

[11] M. Turk and A. Pentland, "Eigenfaces for recognition," Journal of Cognitive Science, pp. 71-86, 1991.

[12] R. Tjahyadi, W.-Q. Liu, and S. Venkatesh, "Application of the DCT Energy Histogram for Face Recognition," 2nd International Conference on Information Technology for Application (ICITA 2004), pp. 305-310.

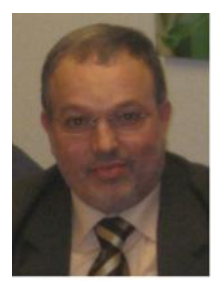

Samir Akrouf was born in Bordj Bou Arreridj, Algeria in 1960. He received his Engineer degree from Constantine University, Algeria in 1984. He received his Master's degree from University of Minnesota, USA in 1988. He received his $\mathrm{PhD}$ degree from University of Setif Algeria. Currently; he is an associate professor at the Computer department of Bordj Bou Arréridj University, Algeria. He is an IACSIT member and is a member of LMSE laboratory (a research laboratory in Bordj Bou Arreridj University). He is also the dean of Mathematics and Computer Science Facultyy of Bordj Bou Arreridj University. His main research interests are focused on Biometric Identification, Computer Vision, Computer Networks and Social Nnetwork Analysis.

Selmani Larbi was born in El Eulma Algeria in 1955. He received his bachelor degree in physics in 1978 from Algiers University. He received his PhD in 1985 from INSA de Lyon University France.

Currently; he is a professor at the Electrical Engineering Department of Bordj Bou Arréridj University, Algeria. He is also the Dean of Technical Science Faculty of Bordj Bou Arréridj University, Algeria. His main research interests are focused on Biometric Identification, Distant Learning, Simulation and Computer Aided Design.

Boubetra Djamel was born in Bordj Bou Arreridj Algeria in 1960. He received his engineer degree in Mechanics in 1984 from Setif University. He received his PhD in 1992 from Humboldt University Berlin Germany.

Currently; he is an associate professor at the Electrical Engineering Department of Bordj Bou Arréridj University, Algeria. He is also the vice director of foreign relations. His main research interests are focused on Biometric Identification, Distant Learning, Simulation and computer aided design.

Messaoud Mostefai was born in Bordj Bou Arreridj, Algeria in 1967. He received his Engineer degree from Algiers University, Algeria in 1990. He received a DEA degree en Automatique et Traitement Numérique du Signal (Reims - France) in 1992. He received his doctorate degree en Automatique et Traitement Numérique du Signal (Reims - France) in 1995. He got his HDR Habilitation Universitaire: Theme: «Adequation Algorithme /Architecture en traitement d'images » in (UFAS Algeria) in 2006. Currently; he is a professor at the Computer department of Bordj Bou Arreridj University, Algeria. He is a member of LMSE laboratory (a research laboratory in Bordj Bou Arreridj University). His main research interests are focused on classification and Biometric Identification, Computer Vision and Computer Networks. 